\title{
La religión como configuración dialéctica del espí- ritu absoluto de Hegel
}

\author{
Dies ist die Hauptsache, und die Bedeutung der \\ Geschichte ist, dass es die Geschichte Gottes \\ ist.
}

Lasson, II, II'. 166.

La Religión es la segunda configuración del Espíritu Absoluto, según Hegel. Religión quiere decir "elevación del espiritu de lo finito a lo infinito", y el camino, el modo y la realización de esa elevación y de su coincidencia final es lo que tratará de mostrar Hegel en sus Lecciones sobre Filosofía de la Religión. Por ello, la Religión podrá definirse también como "la unión del espíritu finito con el infinito" ${ }^{1}$. Nótese que se trata de Filosofia y no de Teología, ni siquiera de la "teología camuflada" de que se mofaría Nietzsche. $Y$, precisamente, porque la Religión es también una forma dialéctica de la autorrealización del Espíritu. $\mathrm{Y}$ ha de quedar absorbida, suprimida, anulada, adentrada o reasumida en y por la Filosofía ${ }^{2}$. Como tal

1. Die Religion ist der Geist als Bewusstsein seines Wesens..., das in Begriffe des Geistes liegt, ist das, was wis die Erhebung des Geistes vom Endlichen zum Unendlichen genannt haben: (Lasson, II, II ${ }^{\mathrm{a}}, 6$ ). Die Religion ist die Einheit von Endlichem und Unendlichem: (Ibid., 119). Mirada desde el espíritu finito sería más clara la definición de Religión como "die Beziehung des Geistes auf den Absoluten Geist", es decir, la relación del espíritu (finito) con el Espíritu Absoluto. $Y$ mirada desde Dios, la definición de "el saberse del Espíritu divino por la mediación (durch Vermittlung) del espíritu finito": (Ibid., I, 151). Citaré siempre por esta edición crítica de G. Lasson, 1925-1929, y que en las Obras ocupa los vols. XII-XIV. La reimpresión de F. Meiner, en dos vols., Hamburg, 1966, engloba en cada volumen dos partes con distinta paginación. El modo de citar lo haré con referencia al volumen y parte, seguido de la página, v. g. I y I, II a (primer vol.) y II, II a, para el segundo y segunda parte.

2. De tal manera entra en el meollo de la Filosofía hegeliana que el objeto de esta parte estima Hegel que es lo definitivamente verdadero (was schlechthin wahrhaft) y en el que se solucionan todos los enigmas del mundo (in der alle Rätsel der Welt gelöst sind). Dios es el resultado (das Resultat) de todas las otras partes de la Filosofía. $Y$ aqui el fin se trastrueca en comienzo": (Wer$k e$, XII, 1 y 33). Ya en las Lecciones sobre Filosofía de la Historia Universal había despachado el tema de un modo bien poco propicio para la Teología: "Se ha 
forma dialéctica es como únicamente va a ser considerada aquí y no en ninguna de las otras vertientes posibles. Por otra parte, aunque una visión superficial pudiera sugerir lo contrario, Hegel tampoco pretendía hacer una Historia de las Religiones, sino demostrar el entramado interno del devenir histórico en las distintas "representaciones" de la divinidad ${ }^{3}$.

Con todo, para facilitar la comprensión de este acotamiento y poder, a su vez, tener una visión panorámica del campo intelectual sobre el que se extiende esta Obra de Hegel, que ha podido llamarse, no sin cierta hipérbole, como el Sanctissimum de una Summa universalis o summa summe theologica ${ }^{4}$ adelantaré aquí un esquema general de la misma agrupando algunas divisiones de títulos y subtítulos y obviando lo que sea de exclusiva y esotérica terminología hegeliana para que esa comprensión sintética sea más accesible.

Después de una larga introducción sobre la noción, objeto, des-

llegado en los últimos tiempos a tal punto que la Filosofía tiene que hacerse cargo de la Religión, incluso contra algunas formas de Teologia (Traduc. Gaos, Revista de Occidente, I, 1946, 30-31).

3. Die Geschichte der Religionen ist nicht unser Zweck... La razón es que debe encontrarse una necesidad superior que explique la contingencia y variabilidad del hecho religioso, las determinaciones concretas de las Religiones: Die Geschichte der Religiones in diesem Sinne zu studieren... ist unsere Aufgabe: (LASSON, I, 164). Me interesa que quede subrayada esa delimitación del tema. La problemática que suscita y ataca la Filosofía de la Religión de Hegel es amplia y erizada casi siempre de dificultades hermenéuticas. La ingente bibliografía que ha provocado está todavía muy lejos de cubrir las posibilidades interpretativas. Un libro global sobre la Religión en Hegel, desde el punto de vista de un teólogo católico, con abundante bibliografía y buen encuadramiento histórico es el de HANS KÜNG: Menschwerdung Gottes. Herder. Freibunrg im ,B. 1970 ; 704 págs. (Traduc. esp. Herder, Barcelona, 1974). Desde una perspectiva estrictamente dialéctica, y con la pretensión de ser exhaustivo en análisisis de nuevos textos e interpretación, podría ser el de A. CHAPELLE: Hegel et la Religion I, II, III y IV. Paris, 1967-1971. Ya la planificación de la obra y su aparición salteada del orden de las partes proyectadas favorece bien poco la clariđad buscada, y en general se ha podido decir de ella que es más oscura que la lectura directa del mismo Hegel. Es interesante el volumen de "Los textos teológicos de Hegel", y, en todo caso, yo indicaría comenzar por el estudio del vol. III: La Théoloğ̌e et l'Eglise, La dialectique, deuxième partie, en contra de la opinión del propio Autor. Como captador y reflejo del pathos místico y teosófico de esta obra de Hegel, yo señalaría el libro de I. ILJIN: Die Philosophie Hegels als kontemplative Gotteslehre. Bern, 1946. La mejor producción de varios teólogos protestantes, v. g. W. Pannenberg, está influenciada muy directamente por. Hegel, especialmente en la concepción de la Historia como revelación de Dios y pueden servir de iniciación a la lectura de Hegel. Sabido es, por otra parte, que la casi totalidad de los "teólogos de la muerte de Dios" proceden también linealmente de una mentalización hegeliana, si bien chata $\mathrm{y}$ empobrecida. Un informe sucinto y crítico sobre bibliografía hegeliana en torno a los años 60-67, puede verse en P. HENRICI: "Hegel und die Theologie": Gregorianum 48 (1967) 706-746; cf. R. FLOREZ: "La actual apelación a Hegel": Arbor 269 (1968) 1-27.

4. H. KUUNG, Menschwerdung Gottes; cit. en pp. 427-428. 
arrollo, método apropiado y temática de los campos connexos de Filosofía y Teología, viene la división de la obra en tres grandes partes:

En la primera se estudia el concepto de Religión; el saber inmediato, el sentimiento religioso, la representación religiosa, la dialéctica de lo finito, la mediación absoluta (es aquí donde Hegel coloca, una primera vez, las "pruebas" de la existencia de Dios), y, finalmente, la realidad (diriamos externa) de la Religión; el culto, la Religión y el Arte y la Religión y el Estadó.

La. segunda parte trata de La Religión determinada, es decir, de las formas de la manifestación de la Religión, con dos grandes apartados: A) La Religión de la Naturaleza (cifrada especialmente en las religiones orientales sobre la que se estudian el estado primitivo, paraíso, caída, magia, culto a los muertos, el Tao, culto a los genios, brahamanismo, religiones del bien y del mal, luz y tinieblas, simbolísmos y zoolatría. Los grados ascendentes de esta religión determinada aquí los llama Hegel: Religiones inmediatas, de la substantividad, de la subjetividad abstracta y del enigma. B) Religiones de la individualidad espiritual. Hegel trata y reflexiona aquí sobre la Religión de la sublimidad o excelsitud (Erhabenheit) que sería la propia de Israel, religión de la belleza o individualidad bella, que sería Grecia y religión de la finalidad cuya expresión sería especialmente Roma. En la religión de la sublimidad está el interesante tratamiento sobre "la aparición de la esencia" (die Erscheinung des Wesens) que viene a ser una descripción fenomenológica del modo dialéctico de entender la creación como la "posición" de lo "Otro" de Dios. Previo a este tratamiento está un nuevo ataque a las pruebas de la existencia de Dios y de las "representaciones" de Dios $y$, por fin, los temas de lo trágico, el culto de los misterios y oráculos, de nuevo Religión y Estado, etc., y la justificación del paso al grado superior de la tercera parte.

Esta tercera parte se titula "La Religión perfecta (vollendete) o manifiesta (offenbare)": La Religión absoluta. Hegel se refiere con estas varias denominaciones, como es sabido, al Cristianismo. Después de precisar el alcance conceptual de este nuevo grado o nivel histórico logrado y visto como definitivo y de analizar "la positividad y espiritualidad de la Religión absoluta", Hegel divide su tratado en la conocida fórmula trinitaria de los tres reinos: El reino del Padre, el reino del Hijo y el reino del Espíritu. De importancia especial (aún para hoy, si bien no para el enfoque que hemos adoptado aquí) pueden considerarse los apartados dedicados al concepto cristiano de Dios, al tema "representativo" (mítico) de la caída o 
pecado original y a los de la reconciliación mediante la Humanización o encarnación (Menschwerdung) de Dios y la fe y culto de la Comunidad eclesial. Hegel subtitula el "reino del Espíritu" con estas palabras: el Espiritu y la Iglesia. Creo innecesario añadir que por encima de las muchas expresiones tradicionales en esta última parte, nada queda sin trasponer y cambiar de sentido y que no se puede hablar de ortodoxia alguna, ni protestante ni católica, si bien Hegel cuida de no darle relieve de otro signo, en el recuerdo y temor de lo ocurrido con su predecesor Fichte. Entiéndase que todo es aquí hegeliano, estrictamente hegeliano, y elaborado en vista a dar una interpretación y una exégesis y, a la vez, un método hermenéutico de la Historia de las Religiones. El "Deus abscónditus" pasa por su "viernes Santo especulativo", como en una sinfonía inacabada y perenne, hasta convertirse en el "Deus revelatus". En esta sinfonía, los últimos acordes mantienen y conservan todas las vibraciones y modulaciones de los primeros; pero además revelan la luz que ha brotado de todas las trabajosas "apariciones" y "oposiciones" divinas a través del mundo y de la conciencia del hombre. "El dominio de la necesidad antigua respira tristeza", nos dice Hegel. También en esta Filosofía de la Religión, sobre la que "pensar" es "pasar" como historia del "concepto" y de la vida misma de Dios, se cierne, al final, un halo de melancolía profunda: la del sometimiento del hombre a la espera y escucha del acaecer histórico para tomar conciencia de las mismas. Es el precio de esta extraña y transparencial revelación. Sólo mediante ella, piensa Hegel, puede llegar en el hombre a cobrar sentido su anhelada meta: la de ver y sentir "unidos lo finito y lo infinito, lo humano y lo divino" que es, justamente, lo que todos los grandes pensadores místicos y dialécticos han pretendido alcanzar ver en la divinidad: la coincidentia oppositorum.

Volvemos, con ello, a nuestro lugar de acotamiento del tema. Con la Filosofia de la Religión engarzamos la muesca del penúltimo eslabón que va a cerrar el círculo del pensamiento hegeliano. Como podrá observarse, la Religión ya no es considerada aquí por Hegel como "positividad" opresora en su realización histórica e institucionalizada, como ocurría con el Cristianismo en los Escritos teológicos de Juventud". La Religión ya no engendra "alienación" porque Hegel ha elaborado su sistema y sabe cómo el extrañamiento ha de

5. Cf. R. FLOREZ, "El Dios de Hegel" Estudio Agustiniano 2 (1967) 479514, ID., "El Dios dialéctico": Estudio Agustiniano 5 (1970) 3-50, con un enfoque general del tema y textos de ese período de juventud. 
convertirse en apropiación. La religión es ahora proceso de liberación del hombre, liberación de lo humano y lo finito por su inmersión en lo infinito o su absorción por el absoluto. El objeto de la Religión es ahora el más elevado (höchste) de todos. El hombre es conciencia eterna en el manantial de su pensamiento... $\mathrm{Y}$ "por ser Dios el principio y la meta de nuestro hacer, iniciar y querer, todos los hombres y todos los pueblos tienen una conciencia de Dios, de la substancia absoluta, como de la verdad, que es su verdad y la verdad del todo... La conciencia religiosa, el saber y el sentir de Dios, es como su vida superior, su verdadera dignidad, el domingo de su vida..." En el recogimiento religioso, la imagen de lo Absoluto, no es un ideal inasequible o un utópico o inaccesible más allá, sino que "brilla en la obscuridad del presente temporal, como la substancia concreta presencialmente actuante..." ${ }^{6}$. Hemos de dar por liquidado el famoso y falso conflicto entre Razón y Fe. Porque "es la locura más absurda de nuestro tiempo el decir que el pensamiento hace mal a la Religión o que la Religión será tanto más sólida cuanto más renuncie a pensar. Esto significa ignorar las condiciones del espíritu" ", porque "la religión es el conocimiento que tiene de sí mismo el espíritu divino por la mediación del espíritu finito" 8 .

Este es el programa que veremos desarrollarse en la Filosofía hegeliana de la Religión. Como en la consideración de la Historia Universal, Hegel parte aquí de que el espíritu es la realización de su concepto en el devenir histórico; es "llegar a verse y concebirse como un mundo presente, a tenerse ante si, como el artísta obedece al impulso de poner su esencia ante sí y gozarse a sí mismo en su obra" 9. Por ello, pasos históricos y pasos metodológicos van a ser una misma cosa ${ }^{10}$. Una vez llevada a sus últimos desvelamientos esta doctrina, realizada su más plenaria secularización, convertido lo "fanum" en "profanum", la Aufklärung quedará radicalizada y, a su vez, superada. La verdadera revelación no es más que el modo del autodesvelamiento histórico y procesual de la Razón misma. Y Dios no será más y nada menos que su propia historificación dialéctica.

6. LASSON, $1,2-4$.

7. LASSON, $135 ; 155$.

8. LASSON, $148 ; 151$. p. 96 .

9. Lecciones sobre la Filosofía de la Historia Universal. Trad. Gaos; cit. en

10. "Methode ist der sich explizierende Begriff, nich anderes, und dieser ist nur einer... Das Fernere, die ganze Abhandlung... ist nicht anderes als die Entwicklung des Begriffs... und dies Setzen macht die Realitat des Begriffs aus, vollende deselben zur Idee": (LASSON, I, 63). 


\section{LA IDENTIDAD MEDIADA}

Al hablar Hegel del concepto metafísico de Dios trata de situarnos inicialmente en la noción de inmediatez. Dios es la unidad absoluta. Pero la inmediatez del concepto equivaldria, como la noción pura de ser en la Lógica, a la noción de la nada. La unidad de Dios, por el contrario, es la de "uno y todo", हैy $\pi \alpha \tilde{\imath} \pi \tilde{\alpha} \nu$, el uno que de alguna forma es ya lo otro. La verdadera noción de la "inmediatez" de este concepto es que dicha inmediatez se dirige espontáneamente hacia la mediación (treibt sich aber selbst zur Vermittlung fort) $\mathrm{y}$ es en la verdadera Religión donde se llegará a tener plena conciencia de la auténtica noción de Dios ${ }^{12}$. En el primer momento abstracto, Dios sería algo indeterminado (Unbestimmtes). El Dios real no es "la Identidad inmediata" o la "no mediata identidad" Dios como la "inmédiatez de sí mismo" es sólo el punto de arranque del concepto ${ }^{13}$. $Y$ esa falta de contenido no responde en absoluto al concepto vivo que Dios es, ni al concepto vivo que late en mi pensamiento sobre él. En realidad, el concepto propio de Dios contiene en sí la mediación. Ahí está la raíz y el camino para las pruebas de su existencia:

"El concepto abstracto, metafísico de Dios es altamente simple o más bien la simplicidad misma. Pero nuestra más profunda representación de Dios no se puede acomodar a esta determinación". Basta ahondar previamente en la noción de concepto. "Una determinación conceptual no es algo que esté en si en reposo, sino que está en movimiento, es esencialmente acción o actualidad. Por ello, todo concepto es ya mediación; el pensamiento es ya en sí esa mediación, inquieta, activa, y si el pensamiento es determinado, contiene ya la mediación en sí". Dicho esto sobre la naturaleza del concepto, aparece claro que no debemos tomar la mediación en un sentido subjetivo, sino de forma que sea igualmente una mediación objetiva de Dios en sí mismo. La mediación que aparece evidente en el terreno lógico, está incardinada, como realidad actuante, en la Idea misma ${ }^{14}$.

11. LASSON, I, II'a 5 .

12. LASSON, II, II $, 57: \ldots$ diese unmittelbare Identitat..., als unmittelbare Identitat.

13. LASSON, I, II $\mathrm{a}, 38,39$.

14. LASSON, I, II , 42-43: "Begriffsbestimmung, Begriff überhaupt ist für sich nicht ein Ruhendes, sondern ein sich Bewegendes, wesentlich Tätigkeit... Den Begriff haben wir also vor uns als Vermittlung, und die Gottesbeweise sind ebenso Vermittlung; Gott soll mit einer Vermittlung dargestellt werden. In beiden ist so dasselbe... Nach dem, was über die Natur des Begriffs bisher gesagt worden ist, erhellt, dass wir die Vermittlung nicht so subjektiv, sondern so fas- 
Poseer la mediación significa e importa además la noción de ser-abierto, de tener y poner ya dentro de sí la determinación del ser-con. El ser finito tiene, por ello, su verdad en el Ser, en la abertura del Ser hacia lo otro, que es a la vez limitación y determinación y, en ambos casos, comunicación. "Pero este Ser se limita a sí mismo, pone frente a sí lo Otro, se comunica. Y este comunicarse (Mitteilen) es lo positivo de lo Otro... De esta forma el ser absoluto es para la intuición el ser abierto en cuanto determinado para un Otro, y esta es su primordial y absoluta división" ${ }^{15}$.

A partir de aquí quedan ya francos los caminos para comprender la diversidad de apariciones o "representaciones" de Dios, que van a configurar las diversas formas de Religión y en las que cada una va a aportar su novedad positiva en la determinación del concepto objetivado de Dios y en una precisa configuración religiosa. La plenitud del concepto de Dios y de Religión se verá reflejada en la forma última de estas "representaciones" que es el Cristianismo, singularmente por la plenitud formulada en la noción de Trinidad y de Humanización o encarnación de Dios ${ }^{16}$.

Hegel insiste, con todo, en otro detalle que por su expresiva radicalización no quiero dejar sin formular. Se trata de lo que Hegel llama "la finitización" de Dios. El verdadero Dios es el que se mediatiza, se esencializa, se fenomenaliza, se finitiza, a través del proceso histórico. Tanto que Hegel no duda en afirmar que es este el primer y más auténtico "atributo" de Dios, si de atributos pudiera tratarse, y en el que toda la atribución de predicados ha de encontrar su fundamentación. Porque, a la vez, esta finitización conlleva una transfinitización de lo finito, una elevación de lo finito a la divinidad por la mediación de la infinitud en él. Lo finito se diosifica o diviniza, llegando así a la negación de la finitud. Esto es lo que hace la concepción y puesta en marcha de la Dialéctica como alma de la Religión, mejor, como corazón o latido en la Historia de las Religiones,

Aunque para la Exposición de esta doble idea Hegel multiplica,

sen müssen, dass sie ebenso eine objektive Vermittlung Gottes in sich selbst, dass die Vermittlung, die im Logischen ist, in der göttlichen Idee selbst enthalten sei, und insofern die Vermittlung so gefasst wird, ist sie eine notwendige Bestimmung, notwendiges Moment. Die Gottesbeweise müssen sich als notwendiges Moment, als ein Fortgang, eine Tätigkeit des Begriffs selber zeigen".

15. LASSON, I, II ${ }^{a}, 46$ : “... So ist dem Anschauen das Absolute Sein, wie es für ein Anderes ist; es ist offen als bestimmt für ein Anderes, oder es ist seine absolute Urteilung", 100 .

16. Cf. también las Lecciones sobre la Filosofía de la Historia Universal, 
repite y estructura un sin fin de textos y combinaciones de la terminología dialéctica, me voy a limitar aqui a algunos de los que estimo más claros y decisivos y que apuntan respectivamente a ambos costados de lo enunciado.

"Dios se finitiza (verendlich sich), se da a si mismo la determinación". Esto que Hegel reconoce que puede parecer no convenir a la esencia divina, se patentizará, si ahondamos en el concepto de Dios que es incluso generalmente admitido. Todos admitimos hoy a Dios como creador y si ahondamos proyecciones mitologizadas, esto es una honda verdad y una muy clara atribución verdadera de Dios. Si previamente a la creación no existe nada, "Dios se determina a sí mismo..., se pone como otra cosa y deviene lo otro. Dios y el mundo son dos, pero sólo Dios es y es "por la mediación de si consigo mismo (durch Vermittlung seiner mit sich). "Crear es la actividad, y ahí reside la diferencia y ese es el momento de lo finito... Dios es este movimiento y sólo mediante él se puede concebir como Dios vivo: Dios sin el mundo no sería Dios" ${ }^{17}$.

Dios no deviene espíritu absoluto más que mediante el conocimiento de sí mismo y de su otro. "Pero de esta suerte no puede ser mediatizador (vermittelt) más que por la conciencia del espiritu finito: debe, por ello, finitizarse ( $z u$ verendlichen hat) para mediante esta finitización (Verendlichung) serse sabedor de sí mismo" ${ }^{18}$. Esta es la forma de la "identidad mediada" que nos descubre el verdadero Dios. La religión ha de llevar al espíritu a ser consciente de su esencia. Después de esa división, de esa escisión (Trennung) divina, de esa separación, ha de venir la unión. Y esto es la meta de lo religioso: la elevación del espíritu finito a lo infinito. Esta elevación se realiza "mediante la negación de la finitud" (durch die $\mathrm{Ne}$ gation der Endlicheit). Es de esta manera como la conciencia religiosa consiste en que el sujeto finito tenga por objeto su esencia. La subjetividad finita es en sí misma un momento de la subjetividad infinita. La unidad de ambas es el concepto de Religión" ${ }^{19}$.

Sólo desde estos presupuestos es como cabe dar inteligencia y comprensión a lo que Hegel llama las "pruebas" de la existencia de Dios. Aparte de los lugares que en la Filosofía de la Religión le de-

17. LASSON, I, 146-148: “...Gott ist ebenso auch das Endliche, und Ich bin ebenso das Unendiliche; Gott kehrt im Ich als in dem sich als Endliches Aufgehobenden zu sich zurück und ist Gott nur als diese Rückkehr. Ohne Welt Gott ist nicht Gott".

18. LASSON, I, 151.

19. LASSON. II, II ${ }^{\mathrm{a}}$, 4-6. 
dica, Hegel había consagrado otros cursos a su exposición particular ${ }^{20}$. Aquí se trata de encuadrarlas en una más amplia perspectiva y sacar las consecuencias para la fundamentación de las vivencias religiosas. Por eso Hegel nos dice que trata de honrar ( $z u E h-$ ren bringen) las tan denostadas pruebas en los tiempos modernos. El punto de partida ha de ser que "lo finito supone lo infinito". El pensamiento comprende su unidad y su diferencia. Esta unidad es a la vez mediadora (das Vermittelnde) y es el presuponerse (das Voraussetzen) de lo infinito mediante lo finito. El ser del Uno es el ser del otro, esta es la proposición fundamental. $Y$ todo depende 0 nace de esta conexión" ${ }^{21}$.

"Probar", por consiguiente, no ha de consistir más que en descubrir o desvelar o hacer patente a la conciencia esa conexión óntica de la presencia de lo infinito en lo finito. Se trata, pues, de concienciación y de hacer explícito algo que subyace o está implícito, aunque real, en el ser de lo finito. Pero esto ha de comprenderse en dos niveles diferentes: el individual y el histórico. El histórico ha de enriquecer el individual e irlo perfeccionando. Por el hecho de tratarse de autoconcienciación, puede hablarse de ella desde Dios en la medida en que esa concienciación logra el que el Espíritu devenga Absoluto, es decir, sea autogeneración de Dios en cuanto revelado como Espíritu, en cuanto es autodesarrollo y siempre actividad. En el hombre es desvelamiento de sí mismo en cuanto pendiente de lo infinito, conexionado con él y siendo mediante él. De ambos modos, puede hablarse de una revelación ontológica de la verdad de Dios. En ambos también se trata de pasar del en-sí al para-sí, mediante la desvelación de la presencia de mutua, aunque diferente, pertenencia del uno al otro. De ahí que para Hegel, la única prueba absolutamente válida, y que puede dar viabilidad posible a todas las limitadas pruebas que puedan hallarse, es la del argumento ontológico y que consiste en ir del pensamiento autogenerado en mí por la presencia de Dios y la afirmación evidenciada de su existencia. Trasladada a las formulaciones tradicionalmente conocidas, sería una forma, totalizante y radicalizada, más en lo óntico que en lo lógico — si bien para Hegel serían equivalen-

20. Hay una traducción española de esos Cursos: Lecciones sobre las pruebas de la existencia de Dios, editadas por Aguilar. Madrid, 1970, con traducción del alemán y una nota introductoria de Guillermo R. de Echandía, y tres apéndices sobre el enjuiciamiento hegeliano en torno a la crítica kantiana de la demostración cosmológica y las demostraciones teleológica y ontológica.

21. LASSON, I, II a, 43: "Das Sein des Einen ist das Sein des Andern", sit der Obersatz. Auf diesen Zusammenhang kommt alles an. 
tes- del aforismo pascaliano y de resonancias agustinianas: Tú no me buscarias si previamente no me hubieras ya encontrado...

Ya en las lecciones de Jena, más intuitivas y poéticas que lass de Hegel maduro, en el que prima la exactitud de la terminologia frente a las formulaciones evocadoras y sugerentes, Hegel habia dicho que Dios era la soledad del hombre ${ }^{22}$. Es decir, cuando el hombre está silenciosamente consigo mismo, contemplando el hontanar surgente y circundante de su pensamiento, y siente la oquedad, el desfondamiento de su finitud trascendida, como lanzada $\mathrm{y}$ connotando la propia infinitud, Dios aparece como ese silencio misterioso que llena y ensancha ilimitadamente la soledad, que, como en la experiencia de los místicos, viene a resultar silencio sonoro y soledad en compañía.

"Se debe decir que lo Absoluto es, en esencia resultado, por lo que sólo al final llega a ser lo que es en verdad", nos había dicho en la Fenomenología. También en el hombre es el resultado de su propia realización en cuanto ser que dialectiza su propio ser implícito y latente, aunque no por ello menos real y actuante en todas las dimensiones de su humanidad.

La contextura dialéctica de las pruebas debe lograr como meta el mostrar como evidenciada la mediación interior del espíritu infinito en el hombre en cuanto finito, para concienciar la razón de esa finitud insatisfecha, hacerla patente y abismática, anonadante y anhelante, a la vez, de sustentación para, al no poder soslayarla ni enmascararla, hacerle saltar al hombre a la exigencia racional de la infinitud.

22. Werke, $\mathrm{XX}$ : Jenenser Realphilosophie, 270-272: “Gott ist überal, ist reines Denken; wenn insgeheim der Mensch mit sich selbst ist, ist eben seine Einsamkeit, sein Denken bei ihm". 


\section{H. - LA PROCESION DE LOS DIOSES}

La dialéctica de lo Absoluto se realiza en el medio temporal que es la Historia. Como su obrar reincide en su ser, la Historia es la realización de su esencia, su esencialización. La mediación pasa, como hemos dicho, por "la revelación interior de Dios en el espíritu del hombre". El movimiento dialéctico del pasar y del pensar, del irse "mediando", va "de lo contingente a lo necesario y de lo finito a lo infinito". El hombre "proyecta" las imágenes de Dios en conexión con los medios que la Historia y su entorno temporal y espacial ha puesto para configurarlo. $Y$ Dios se "tipifica" en las formas de los dioses históricos de las distintas religiones, en el camino de ascensión hacia la Religión manifiesta o absoluta. El proceso es progreso tánto en la óntica de la divinidad como en su concienciación así como a la vez en la elevación del hombre hacia la unión con la divinidad y su toma de conciencia de la misma. Esta es la nueva Lógica trascendental de la Historia. Vista desde el exterior es una procesión de dioses que ligan cada uno al hombre a un culto y a un modo peculiar de adoración, de normas morales y ascéticas para lograr con sus prácticas la deseada, consciente o inconscientemente, unión con Dios. Esta es la Historia de las Religiones. Comprender parte de su enigma es, por ello, comprendernos también a nosotros mismos y comprender, a la vez, la esencia de lo Absoluto. Es antropología y es Teodicea. En cada momento histórico, Dios se autorrealiza y autocomprende en el tránsito por el quehacer y el saber de lo finito y el hombre configura a su Dios como expresión de su peculiar y temporalizado pulso humano, de su pensamiento $\mathrm{y}$ sentimiento, de sus temores y de sus ansiones, de sus ilusiones y de sus miedos, de sus anhelos de felicidad y de los riesgos amenazadores de no poder lograrla. De ahí que la Religiones nos ofrezcan cada una diversas "representaciones". de la divinidad, convergentes en algunos modos de expresividad y divergentes en otros, según la captación especial, limitada y concretizada por cada situación humana, personal o de grupo, sin poder llegar a la comprensión sciente de sí misma, que sería ya el grado último de la Filosofía. Constatar esto, ahora y aqui, y de esta manera, es ya Filosofia; pero antes ha debido ocurrir la realización "representativa". Como siempre, "el búho de Minerva no levanta su vuelo hasta la caida de la tarde"... Y aquí, el día de esa tarde es la Historia de las Religiones.

Lo importante es saber que cada eclosión histórica de una nueva determinación de lo absoluto, viene presidida por la razón divi- 
na. Hegel se refiere como a una frivolidad y estupidez al dicho, a veces socorrido, de que la religión la inventaron los sacerdotes. Cabria, entonces, preguntarse retrospectivamente quién había inventado a los sacerdotes y por qué arte de birlibirloque habían aparecido en el mundo. "La razón del hombre, la conciencia de sus eșencias, es la razón general, y es justamente lo divino en el hombre (das Göttliche im Menschen)... Es el espíritu en cuanto éspíritu. de Dios, que no está más allá de las estrellas, sino que es un Dios presencial, como espíritu en los espíritus... Una religión es un producto (Erzeugnis) del espíritu divino, y no invento humano, sino obra del espíritu divino expresándose en ella" "23 "En las religiones los hombres han expresado la conciencia que tienen del objeto supremo; son pues obra de la razón y es absurdo creer que han sido los sacerdotes quienes las han inventado para engañar a los pueblos" ${ }^{4}$. "Los pueblos han depositado (niedergelegt) en las religiones la forma de cómo se representaban (vorstellten) la esencia del mundo, de la sustancia de la naturaleza y del Espíritu e igualmente el modo de relación que el hombre tenía con ellas" ${ }^{25}$. Pero además, "la Religión, la representación de Dios... constituye el fundamento de un pueblo. La Religión es el lugar donde un pueblo se da la definición de lo que tiene por verdadero... y la idea que el pueblo tiene de sí mismo". Es una pena tener que constatar que esta conexión necesaria se haya intelectualmente quebrado y olvidado: "la inteligencia moderna ha hecho de Dios una abstracción, algo más allá de la conciencia humana, como un muro desnudo y férreo sobre el cual el hombre se rompe la cabeza" ${ }^{26}$. En resumen y síntesis: aunque la iniciativa venga de la "razón divina" - base inexorable y punto siempre de partida-, ciñéndonos al fondo de la conciencia subjetivada, "la representación que el hombre se hace de Dios corresponde a la que el hombre se hace de sí mismo y de su libertad" ${ }^{27}$. Teología, antropología y etnología contribuyen, cada una en su modo y en su grado, a esta teoria de la divinidad en Historia, a esta configuración articulada de la procesión de los dioses.

23. LASSON, I, 44.

24. R. VANCOURT: La pensée réligieuse de Hegel (P.U.F., 1965) 118, quien remite a las Lessons sur la philosophie de l'Histoire, 151.

25. Werke (Glokner), XVII, 47.

26. Lecciones sobre Fil. de la $H$. Universal. Gaos, 100.

27. LASSON, I, II a , 7: Die Vorstellung, welche der Mensch von Gott hat, entspricht der, welche er von sich selbst, von seiner Freiheit hat. Seria aquí el lugar apropiado para preguntarse qué parte de firme suelo hegeliano y qué constitutiva amputación de Hegel elabora Feuerbach para su Esencia de la Religión. Esta alusión se podría evidenciar con innumerables textos de esta misma obra de Hegel. 
Ya vimos en el esquema de la Filosofía de la Religión que se daban tres tipos fundamentales de estas configuraciones de la divinjdad o religiones. Estos tres tipos pueden desmembrarse en otros más acotados y de nueva denominación, pero sin invalidar por ello la primera división en la triada fundamental.

El primer tipo de la Religión lo forman las Religiones de la Naturaleza. Se llaman de esta suerte porque Dios aparece confundido con la naturaleza, naturalizado en los elementos terráqueos y cósmicos, en las fuerzas que actúan desde el exterior del hombre $y$ frente a él y en las que también él se encuentra inmerso y envuelto. "Religión de la naturaleza quiere decir la religión en su primera determinación, en la unidad de lo espiritual y natural, en la que el espiritu es todavia una unidad con la naturaleza, o sea, que todavía no es libre, no es propiamente espíritu. El contenido es, por todas partes (überall), Dios; pero Dios como unidad natural... "La naturalización es lo que determina en general esta primera forma religiosa. Hay una "neutralidad" (Neutralität) entre espíritu y naturaleza, una mezcla (Vermischung) en la que no cabe la libertad. Esta Religión adopta múltiples configuraciones (Gestalten). Pero a todas las llamamos "religiones de la naturaleza" 0 de la inmediatez" ${ }^{23}$.

Dados estos caracteres, apenas si podríamos darle, en este primer inicio, el nombre de auténtica religión. Si se hace es porque de èl arranca la primera escisión o división, la primera afirmación del espíritu en cuanto tal, es decir, en cuanto libre. La religión comienza a situar lo natural como un momento de lo divino $\mathrm{y}$, a la vez (zugleich) aparece ya en la conciencia religiosa la determinación de la forma espiritual, o sea, la división entre naturaleza-hombre y hombre-espíritu. No se puede decir de ninguna religión que los hombres hayan adorado al sol, a la mar; a la naturaleza. Cuando decimos que han adorado esas cosas, es porque ellas no poseían para los adoradores ese carácter prosaico (dies Prosaische) que tiene para nosotros. Para ellos, en cuanto objetos de religión eran divinos y por ello, representados ya en cierta forma espiritual... La contemplación del sol y las estrellas, etc., como fenómenos naturales es extraña a la religión" ${ }^{29}$.

¿Cómo salir de esta inmediatez? "El hombre no posee aquí más que un conocimiento sensible y natural, y una voluntad también

28. LASSON, $\mathrm{K}, \mathrm{II}, 11-12$.

29. LASSON, K, II, 9, nota. 
natural. Encerrado en esta naturalización tiene un solo elemento que está más elevado (ein Höheres) de la pura inmediatez: es: $l a$ magia. Esta elevación es todavia inconsecuente (inkonsequente), pero se encuentra ya en las tres religiones orientales de la substancia" ${ }^{30}$. En realidad es este elemento el que inicia en todas esas religiones la escisión 0 el inicio de la mediación. Toda la mediación será aquí solamente corporal o ceñida a lo corporal, como son los signos y es el lenguaje ${ }^{3 t}$.

"La primera religión, por ende, si es que queremos llamarla con este nombre consiste en que la conciencia individual de sí se conoce como teniendo un poder sobre la naturaleza, y el ejercicio de este poder es la magia" ${ }_{32}$. El orden explicitativo es el siguiente: "La divinidad aparece en primer lugar como una fuerza de la naturaleza y como una substancia, y se configura en los siguientes grados: se parte de la religión de la magia (directamente entre los esquimales y africanos; indirectamente en las religiones chinas del taoísmo); viene después la religión de la substancialidad (del seren-sí: Budismo y lamaísmo; de la fantasiá; religión india) para pasar finalmente a la religión de la subjetividad abstracta (religión del bien o de la luz; los persas; religión del enigma; los egipcios y sirios)" "з3.

Es por la lucha de este nuevo elemento, que es la magia, por lo que la confusión (Verwirrung) entre la natural y lo espiritual comienza a deslindarse y ha de conducir a la distinción por la que la subjetividad se afirme en su unidad y, generalidad, y desde las tres religiones citadas se monte el tránsito (übergang) al grado de la subjetividad libre ${ }^{34}$.

Entramos, con ello, en el nuevo grado de las Religiones que $\mathrm{He}-$ gel llama de la individualidad espiritual: Israel, Grecia y Roma. Hemos dado un salto de siglos. A pesar de la amplitud que Hegel concede a estas primeras manifestaciones de la religión natural, o mejor, de la naturaleza ${ }^{35}$, se da cuenta también de esta simplificación

30. LASSON, 13, nota.

31. LASSON, 9, nota.

32. LASSON, I, II ${ }^{\mathrm{a}}, 81$.

33. H. KÜNG, : Menschwerdung Gottes, 436.

34. LASSON, I, II a, 13 , nota.

35. Aunque la terminología de Hegel no es precisiva en este asunto, se encarga de formular explícitamente que no se trata de la religión naturai en el sentido en que se habla de ella en la Ilustración, oponiéndola a la religión revelada. Esta forma de Religión apela a la "razón natural", lo que ella descubre de por sí. Y esa expresión la juzga, además, Hegel impropia: Natürliche Vernunft ist ein schiefer Ausdruck: LASSON I, II ${ }^{\mathrm{a}}, 11$. 
que es necesario efectuar. Por eso nos dice que "han sido necesarios siglos de trabajo del espíritu para llegar a realizar el concepto de religión y convertirlo en objeto de conciencia". "La religión se determina por el progreso de la naturalidad hacia el concepto... La verdadera religión sería algo así como el género para el cual se iban danđo como especies las religiones determinadas" ${ }^{36}$. A través de todo este largo proceso histórico hemos de ver siempre un hilo conductor. $Y$ es que "de la misma manera que se determina el contenido de las religiones, es decir, Dios, se determina el espiritu subjetivo, es decir, el espíritu humano que posee dicho conocimiento" ${ }^{37}$. Son dos lados de paralela y correlativa determinación. "Los momentos esenciales del concepto de religión aparecen y se revelan en cada grado de su existencia (histórica). La diferencia entre estos momentos y la forma verdadera del concepto de religión emerge del hecho de que el concepto no se ha realizado todavía en su totalidad". Como ejemplo central coloca Hegel el de la Humanización de Dios. Este concepto atraviesa todas las religiones. Pero sólo llega a explicitarse en realidad y darse plena concienciación del mismo en la Religión cristiana ${ }^{38}$. Otro tanto cabría decir, desde los análisis que Hegel hace, del concepto de la Trinidad en las religiones anteriores a la revelación del Nuevo Testamento.

En la perspectiva de graduación ascensional pareceria que, después de las religiones de la Naturaleza, habría de venir la religión griega. En Hegel mismo se nota el titubeo de encrucijada. Sin embargo, desde el punto de vista dialéctico, no cabe duda en la elección. El primer peldaño en la nueva graduación lo ha de ocupar la Religión de Israel. $Y$ la razón es porque en él se marca más fuertemente la escisión, la negación sobre el grado o momentos anteriores. "Debemos distinguir aquí dos formas de Religión: La Religión de la Excelsitud o de lo sublime (der Erhabenheit), que es la judia y la Religión de la Belleza (Schönheit), que es la griega. En la primera triunfa la separación (Trennung) de la Espiritualidad y de la Naturaleza" ${ }^{\text {9 }}$.

La primera caracterización de la Religión judía hemos de verla en la afirmación del Dios creador. Para Hegel ser creador quiere

36. LASSON, I, II ${ }^{\mathrm{a}}, 4-7$.

37. LASSON, 7.

38. LASSON, 6: "...nur dadurch kommt der Unterschied von der wahrhaftên Form des Begriffs hèréin, dáss sie noch nicht in der Totalität desselben gesetzt sind... Der Gedanke der Menschwerdung z.B. geht durch alle Religionen hindurch".

39. LASSON, I, II ${ }^{\mathrm{a}}, 20$. 
decir que Dios "pone lo Otro" que es el mundo. Y se da la escisión radical y primaria. Hay naturalidad exterior frente a espiritualidad abstracta. Es abstracta esta espiritualidad porque todavía no es "mediada" y es además una espiritualidad limitada, porque el Dios judío es un Dios nacional y no el Dios para todos. El mundo está ahí y Dios está allá. El mundo se ha hecho vulgar y sin latido de divinidad, aunque sometido a la arbitrariedad de un Dios lejano, sin otro contacto con el mundo que su querer y su dominio. El hombre tampoco es libre al tener que estar siempre pendiente de esa arbitrariedad externa del omnipotente y mayestático, abstractamente concebido fuera del mundo. Es sobre estos extremos sobre los que se vendrá a afincar la necesidad dialéctica que realizará la religión griega. Porque en la Religión judía "lo espiritual se desarrolla en su determinación extrema frente a la naturaleza, en la cual el espíritu no es libre. Esta es la cumbre, el ápice, que por un lado pertenece todavia a Oriente y por otro rebasa ya los límites de lo oriental. Asistimos aquí a la transformación del principio oriental" ${ }^{40}$.

Otra forma de escisión que se nos da como concienciada en esta Religión es la del hombre con la naturaleza por medio del relato del pecado original, mito que, para Hegel, pertenece y nos revela un rasgo esencial de lo humano. El "paraiso" es el "parque zoológico" de la inconsciencia del hombre, y la "caída" es justamente la ruptura de esa unidad con lo natural, por medio de la que el hombre comienza a ser y responsabilizarse de sí mismo y a tomar conciencia de que "no es todavía el que debía ser". El hombre comienza así a saberse y sentirse distinto de la naturaleza, a separarse de ella y a tomar sobre sus hombros su propio destino ${ }^{41}$. Ascendiendo en esta concienciación $\mathrm{y}$ dada la escisión anterior, llegaremos al grito del Libro de Job, cuya historia y contenido se coloca ya fuera del pueblo de Dios ${ }^{42}$. El grito de Job es, pues, el grito de la desarmonía fontal, de la búsqueda de otra auténtica reconciliación que no podía ofrecer la Religión judía ${ }^{43}$.

40. Lecciones sobre Fil. de la Hist. Univ., 382.

41. Sintetizo en esos dos párrafos lo que Hegel expone en el tratado sobre Die Religionen der Erhabenheit (LASSON, II, 55-89), uniéndolo a lo expuesto so. bre las Religiones de la Naturaleza acerca de temas como el paraíso, caída, etc.: LASSON, I, II a, 24-29) El hecho de ser este, para Hegel, un lugar del entrecruzamiento de los dos principios referidos obliga al enlace y reiteración.

42. LASSON, II, 74: “...Hiobs Geschichte, Begegnis, Zustand, Inhalt, steht ausser dem Volke Gottes".

43. En las Lecciones sobre Fil. de la Hist. Universal, Hegel formula, si cabe todavía con más fuerza esas primeras características señaladas sobre la Religión judía: "esta representación de que la naturaleza es una criatura y de que Dios es el Señor... pone la base de la nueva relación entre la divinidad y la: natura- 
La Religión de la Belleza va a lograr la unión interna (innige Vereinigung) de los dos factores escindidos, la naturaleza y el espiritu, para expresar "la individualidad corporal consciente de sí". Los dioses griegos van a tener ya rostro humano. "Dios es, en este caso, un contenido múltiple", una individualidad libre, aunque no se llegue aún al concepto de una espiritualidad purificada hasta la libertad absoluta ${ }^{44}$. El contenido de los dioses griegos es el reflejo del contenido de los hombres concretos. "Esta humanidad de los dioses, por lo que toca a su exterioridad es, sin duda, un defecto, pero también lleva consigo la educción de esta Religión". De igual modo que en este Dios el hombre se posee o encuentra a si mismo", la necesidad, el hado, está encima de los dioses y de los hombres. En todo caso, las particularizaciones de la representación de Dios, por los dioses particulares, nacen de la determinación interior del Uno. Los momentos son realizaciones de la subjetividad. Es la totalidad que se particulariza. Reflexionada sobre sí da lugar a los dioses autónomos" ${ }^{45}$.

Se une, pues, lo natural y lo espiritual. El "poder natural" está representado en los dioses griegos como poder de la subjetividad espiritual. Sin olvidar, claro está, que, aunque ennoblecido, lo natural sigue todavía presente, no plenamente espiritualizado. De ahí que tengan una doble faz, siga existiendo la dualidad, lo dual (das Gedoppelte). Esta dualidad se puede ver tanto en su procedencia como en su significación. Artemis de Efeso es todavía asiática. Zeus es el dios del firmamento, Ouranos, fuerza que modifica la atmósfera, el dios del trueno; pero, a la vez, es el padre de los dioses y de los hombres, el dios político, el derecho y la moralidad, del estado, etc.

leza establece la sublimidad de Dios. Encontramos aquí las descripciones de la magnificencia y esplendor de Dios, para quien la naturaleza es un ornamento, una esclava. Esta es la verdadera sublimidad..., completamente extraña a la religión india, cuya confusa elevación se pierde en lo desmesurado, monstruoso y grotesco" (o.c., 183): "Pero el exclusivismo llega aquí al punto de que la adoración de los otros dioses es considerada como obscuridad y tinieblas y no como crepúsculo iluminador por destellos de luz... La religión y el espíritu de un pueblo son siempre algo espiritual y por extraviados que estén, siempre tienen algo de afirmativo, siempre tienen algo de verdad... La presencia divina, una relación de amor divino existe, por lo tanto, en toda religión": (o.c., 385. Con todo, dado que en la idea lógica de la división de las religiones, como dice Hegel, (LASSON, I, II ${ }^{\mathrm{a}}, 21$ ) hemos de ver el Ser, la Esencia y el Concepto (Sein, Wesen, Begriff); la religión judía pone bien de manifiesto, en la idea de creación, la "otroidad" de Dios o la mundanización como "mediación".

44. LASSON, I, II ${ }^{\mathrm{a}}, 20$.

45. LASSON, II, 124: ...jede Momente aber sind die Realisierung der Subjektivität. Die Besonderheit ist hier die Totalität: so in sich reflektierte wird zu selbständigen Göttern. 
Hay una trayectoria evolutiva $y$ ascendente en la religiosidad griega. Hegel la va siguiendo en cierto modo, mostrando sus amplios conocimientos de la mitología en las descripciones de los dioses y las funciones que les tenian asignadas así como en todo lo que se refiere al culto, al tema de lo trágico y a los modos griegos de alcanzar la "reconciliación" 45. A pesar de esa amplitud de conocimientos, e incluso limitándose únicamente a los grandes dioses del Olimpo, Hegel reconoce que seria un esfuerzo inútil (vergebliche Mühe) pretender dar una sistematización ordenada $u$ orgánica de la riqueza de la religiosidad que atraviesa y tiñe toda la vida griega ${ }^{43}$.

La forma peculiar de ostentación de los dioses griegos es la belleza. Porque la belleza para los griegos constituye el órgano de la comprensión del mundo ${ }^{48}$. Por el lado de la substancia, los dioses son la particularización espiritual que en ellos se pluraliza o escinde y por otro lado la limitación de lo particular es elevada oposicionalmente (entgegengehoben) a universalidad substancial. De esta forma se realiza la unidad de ambos: el fin divino se humaniza y lo humano es elevado hacia lo divino ${ }^{49}$. Así nacen los semidioses y los héroes...

Con todo, y aún dada esa conversión de lo divino en representaciones humanas y la elevación de lo humano hacia lo divino, por lo que lo divino recibe siempre una configuración (Gestalt) humana ${ }^{50}$, "el defecto capital de los dioses griegos no es que sean demasiado humanos, o "antropopáticos", sino que lo son todavía muy poco" ${ }^{51}$. Hay representación humanizada y bella, pero no hay todavía verdad integral. Dios queda crucificado (ans Kreuz geschlagen) en el elemento sensible de la forma humana. En esta conversión se muestra que la Alienación de Dios (Entäusserung Gottes) en la forma humana es sólo una parte de la vida divina ${ }^{52}$. Todavía el espíritu no es idéntico a sí mismo en cuanto a su Otro (als sein Anderssein). Falta la conciencia del contenido ${ }^{53}$. Cuando ello ocurra 0 se

46. Cf. LASSON, II, 122-191.

47. LASSON, II, 136.

48. LASSON, II, 147: "Die Weise, wie so der Gott ist, ist also die schöne, von den Griechen hervorgebrachte Gestalt. Diese macht das Organ des Vertehens der Welt aus".

49. IAASSON, II, 132: “..Dadurch erhalten wir die Einheit von Beidem, den götlichen Zweek vermenschlicht, den menschlichen zum götlichen erhoben".

50. Cf. LASSON, II, 146-147.

51. LASSON, II, 144: "...Der Hauptfehler ist nicht der, dass zu viel Anthropopatisches in diesen Göttern sei, sondern zu wenig".

52. LASSON, 146.

53. LASSON, 148 
realice, esta forma humana, concreta, será absorbida (aufgehoben) y puesta como una de las personas divinas en Dios. Será entonces cuando "la representación judia de Dios que existe esencialmente y solamente para el pensamiento, y la forma bella y sensible de los griegos, serán absorbidas y conservadas (enthalten und als aufgehoben) y liberadas así de su limitación" ${ }^{54}$. Ya aparece claro que $\mathrm{He}$ gel está aludiendo al Cristianismo como única forma superadora y plenificante, desde el punto de vista dialéctico, de la religiosidad griega.

Antes de situarnos en ese nuevo grado, es preciso decir algo sobre la Religión romana, o Religión de la finalidad, como la llama Hegel ${ }^{55}$.

La Religión romana tiene por fundamento la finalidad finita, de fines finitos y exteriores. $Y$ por ser exteriores, no se trata propiamente en ella de determinaciones de la esencia divina, no hay nada de ella inmanente en esos fines ${ }^{56}$. La finalidad en esta Religión no ha sido otra que el mismo Imperio Romano, de tal suerte que ha ejercido una potencia abstracta sobre el espiritu de los otros pueblos ${ }^{57}$. El Emperador es la divinidad, el ser divino interior y universal, pero exteriorizado y en el que la Idea ha descendido hasta perder su universalidad, su verdad, su ser-en-si y su ser-para-sí, es decir, su divinidad misma ${ }^{58}$. De ahí el desencanto y la desesperación que va a traer a las almas esta desdivinizada configuración religiosa.

Es el refinamiento y ahincamiento en la finitud misma, la dicha del esclavo abandonado, la desgracia absoluta (das absolute Unglück). Y va a ser justamente ahi donde habrá de residir su mayor potencia dialéctica: el quejido de la escisión y la petición acongojada por un estadio superior. "Es el dolor absoluto del espíritu, la más alta contradicción de sí mismo en sí mismo: y esta contradicción (Widerspruch) permanece en él sin solucción, la oposición sin reconciliación.

En el Panteón romano fueron reuniéndose los dioses de todos los pueblos del Imperio encontrándose y destruyéndose mutuamente.

54. LASSON, 146.

55. También Hegel trata de ella con menos morosidad y simpatía que de la religión de los griegos. Aunque bajo el título de Die Religion der Zweckmässigkeit, en Lasson, II, ocupe las páginas 192-242, el material que más sigue manejándose, como comparación y referencia de tránsito, es la religión griega.

56. LASSON, II, 202 .

57. LASSON, 241.

58. LASSON, 239. 
"El genio romano, este Fatum, ha aniquilado la dicha y la serena alegria de la vida bella y de la conciencia de las religiones anteriores reduciéndolas todas a la unidad y a la igualdad. Este poder abstracto es el que ha ocasionado una insondable desdicha, un sufrimiento universal, que había de ser como los dolores de parto de la Religión de la verdad... La penitencia del mundo, la dejadez de la finitud, la desesperación (Verzweiflung) en el espíritu del mundo al no encontrar su satisfacción en la temporalidad y en la finitud. Pero todo esto sirvió para preparar el terreno a la verdadera religión, porque habia llegado la plenitud de los tiempos".

Es así cómo debía unirse "el principio oriental de la abstracción pura al principio de la finitud occidental". Hegel añade, incluso, una nueva y extraña precisión, la determinación geográfica: el lugar de origen del Cristianismo se coloca geográficamente entre los dos continentes, en el pueblo judio... "Dios se lo habia reservado como (el sitio) del antiguo dolor del mundo. $Y$ es desde alli desde donde la antigua maldición (alte Flucht) será resuelta y desde donde vendrá la salvación (Heil).

Pasamos asi, concluye Hegel ${ }^{59}$, a la Religión cristiana, la religión de la positividad y libertad absoluta y entramos en el círculo (Kreis) de la religión revelada.

\section{LA TRINIDAD}

Aparte del atractivo que le ofrece todo lo triádico, como encuadramiento categorial y recurso expositivo para la explicación del devenir dialéctico, Hegel se encuentra aquí ante una formulación tradicional, que se ha admitido, admirado y expuesto con tan múltiples y refinadas especulaciones que se le presenta como el terreno más apropiado para la incursión de su propio pensamiento y, a la vez, como la mejor cumplimentación teórica y arropada del mismo. Ante el ceñimiento reflexivo con que se adentra en el tema; ante la reiteración insistente y las fórmulas estereotipadas que logra decirlo, y, por fin, ante las apelaciones que en casi todas sus obras, velada o expresamente, hace a él, diríamos que se trata como del cogollo inquisitivo y la fórmula más expeditiva y casi mágica de todo su andamiaje mental. Tomada en toda esta amplitud real y en todo su contenido asuntivo y resolutivo, no cabe duda que este Trata-

59. LASSON, $239 ; 242$. 
do sobre la Trinidad que Hegel hace podría considerarse como clásico y en cierta medida podria aceptar un parangón con otros muchos de la tradición cristiana, sobre todo medieval, e incluso de entrada con el mismo de san Agustín. Cierto que hay algo radical que imposibilita toda comparación de igualdad: los presupuestos doctrinales y vivenciales de que parten. En Hegel no se trata de "la fe que busca inteligencia", sino de "la inteligencia (Razón) que se autocomprende a sí misma" y echa mano de la "representación" que le viene dada por el pasado para autodesvelar, y hacer ver, en cuanto transparenciada su propia esencia, o mejor diríamos, como hasta ahora, hacer patente su propia fenomenalización o esencialización.

Al final del camino recorrido, nos encontramos, pues, con la Religión manifiesta, es decir, autocomprendida y autorevelada. Dios se ha "aparecido" totalmente. La Historia de sus representaciones culmina aquí con la revelación plenaria de Dios en cuanto que es Trinidad. $Y$ esta Trinidad tiene sus nombres: Padre, Hijo y Espíritu. La Historia abre asi su gran secreto, o su gran astucia, y se nos aparece transida por la divinidad y trascendida en ella. La revelación explícita de esta concepción trinitaria de Dios es el centro del mensaje traído y realizado por Cristo, mediante su encarnación en la Historia, mediante su humanización. Visto desde Dios, desde su entrada en el tiempo y desde la misma idea del devenir. Histórico, Cristo es el universal individualizado, la verdad concreta. De ahí que la religión absoluta se llame Cristianismo.

En todas las religiones anteriores, según Hegel. encontramos huellas (Spuren), vestigios o balbuceos de la Trinidad ${ }^{60}$. Pero la explicitación más precisa (nähere Explikation), la representación concreta (konkrete Vorstellung) ocurre sólo ahora, con el advenimiento del hecho cristiano. Hegel confiesa que la palabra trinidad no es la más apropiada para significar el dinamismo dialéctico de lo divino, por su desafortunada (unglückliche) connotación hacia lo numérico. Pero podemos utilizarla a falta de otra expresión más feliz y ante el hecho de que la razón. (Vernunft), en cuanto es actividad, destruye (vernichtet) la captación estática o paralizadora del entendimiento (Verstand) frente a la posible fijación de los números 1.2.3. que pudiera inducir a pensar en tres dioses (drei Götter) o a que son tres los que hacen uno (Drei ist Eins). El obstáculo debe salvarse percatándose de que el lenguaje de lo religioso es siempre

60. Para la Religión oriental, cf. Lasson, II, 56; para la griega y expresamente para Pitágoras Aristóteles y neoplatónicos 59-61. 
imaginativo y de que aquí se trata efectivamente de una simple "representación" (bloss bildlich) y la labor de la razón ha de consistir en elevar este apunte representativo al orden especulativo y concebir con ello lo trinitario como "momentos" del proceso divino o de la divinidad ". "En la Religión cristiana, añade Hegel, no se dice solamente que Dios es una unidad triple (dreieinig) sino también que son tres personas. Aquí el ser-para-sí (das Fürsichsein) es empujado al summun... La contradicción (Widerspruch) está llevada hasta tal punto que ningún intento de borrar lo personal es posible. Dios es uno y las tres personas no son puestas (gesetzt) más que como distintos momentos. La personalidad expresa que la oposición debe ser tomada en su más completa absolutez" ${ }^{62}$. Es decir que 10 nuevo es concreción de lo antiguo, revelación y densificación ónticas, y en el proceso dialéctico de la personalidad de Dios, visto desde la expresión trinitaria "lo tercero es igualmente lo primero" ${ }^{63}$. "Dios se diferencia en sí mismo permaneciendo idéntico a sí mismo. La Trinidad se llama misterio porque su contenido es mistico, es decir, especulativo (=dialéctico, R.F.). Dios solamente puede ser concebido así por el hombre que piensa y que se mantiene en silencio cabe sí. Es lo que los antiguos llamaban entusiasmo, la meditación puramente teorética, el más alto reposo del pensamiento que es a la vez la más alta actividad para poder captar la idea pura de Dios y llegar a tomar conciencia de la misma" ${ }^{64}$.

En realidad, aquí no hay misterio alguno para la razón, aunque lo hay para el entendimiento. Dios es concebido como actividad pura, como ya lo concibió Aristóteles (lo que la Escolástica llamó actus purus). Por eso se dice que Dios es esencialmente creador y que pertenece a su esencia el serlo ${ }^{65}$. Creación es justamente finitización ${ }^{66}$. Tenemos así el proceso cósmico. Pero actividad pura es también el saber (das Wissen). $\mathrm{Y}$ el saber requiere un otro que es 10 sabido. De esta manera "Dios que es uno, en y por sí, se engendra eternamente como hijo y se diferencia de sí mismo. Tal es el juicio (Ur-teil) absoluto. La relación padre-hijo está tomada de la vida orgánica y no se utiliza aqui también más que como "representación". Pero es la forma de expresar el proceso eterno; Dios como pa-

61. LASSON, 64-65; 71-72.

62. LASSON, 71.

63. LASSON, 72: "...das Dritte ist das Erste"

64. LASSON, 69.

65. LASON, II, II , 74: "Gott ist Schöpfer der Welt; es gehört zu Sein, zu seinem Wesen, Schöpfer zu sein".

66. LASSON, 33. 
dre no sería todavía verdadero, lo verdadero implica la diferenciación; además del comienzo ha de serse y captarse como deveniente ( $h i j o$, R.F.) y como fin, es decir, como Totalidad y sólo como Totalidad es espiritu. El quehacer de la Filosofía, frente a esos apuntes formularios de lo representativo, ha de consistir en captar el contenido integral porque es en él donde se muestra "cómo se involuciona dialécticamente el espíritu en este punto medial (Mittelpunkt) como su absoluta verdad" ${ }^{67}$.

Tal vez mirado desde este punto medial y terminal, otra nueva formulación hegeliana aparezca más clara. "El Espíritu es la Historia divina, el proceso de la diferenciación de sí y del retorno y reabsorción de sí en cuanto historia divina, por ende, debe ser considerado en cada una de estas tres formas" ${ }^{68}$.

La relación de esta noción del Dios trinitario con el espacio y con el tiempo la explicita Hegel de esta manera:

Especialmente, la primera forma (Padre) significa su existencia fuera del mundo, inespacial, fuera de la finitud, Dios tal cual es en sí y para sí. La segunda (Hijo) es el mundo, la historia divina en cuanto real (als real), Dios en el ser-ahí (Dasein) plenificándose. Y la tercera (Espíritu) es el lugar interior de la Comunidad (Gemeinde), primeramente en el mundo, pero además Comunidad "en cuanto se eleva al cielo que ya posee en ella misma aquí sobre la tierra, llena de gracia, o en cuanto Iglesia en la que Dios está actuante y presente".

Desde el punto de vista temporal, el primer elemento (Padre), es el Dios fuera del tiempo, como Idea eterna, pensamiento puro de la eternidad. Pero la eternidad, en cuanto es opuesta al tiempo se explicita en y para sí y se divide en pasado, presente y futuro. EI segundo elemento (Hijo) es la historia divina... La Historia divina en cuanto pasado, como lo auténticamente (eigentlich) histórico. El tercer elemento (Espíritu) es el presente... En este tercer elemento, la Comunidad se eleva al cielo, un presente que se eleva esencialmente reconciliado...; es el Ahora (Jetzt) en cuanto perfección pero puesta además en futuro ${ }^{69}$.

Por 10 que se puede observar en las reiteraciones hegelianas, 10 decisivo para la historia es el segundo elemento, el Hijo, y, en el

67. LASSON, 70, nota.

68. LASSON, 65: “...Geist ist die Geschichte, der Prozess des sich Unterscheidens, Dirimierens und dies in sich Zurücknehmens; er ist als die göttliche Geschichte daher in jeder drei Formen zu betrachten".

69. LASSON, 70. 
caso concreto de su realización temporal, el Cristo. El movimiento de la Historia ha quedado aqui representado (vorgestellt) en un Individuo. "Cristo es Dios en cuanto Dios concretizado" ". Y ha sido "para que el hombre cobrara la certeza de la unidad de la naturaleza divina y humana por lo que Dios ha tenido (müsste) que aparecer asumiendo la carne en el mundo ${ }^{71}$. Es este el momento más grave (das schwerste) de la Religión. Dios aparece en forma humana y lo increíble, (Ungeheure) es que nosotros hayamos visto esta necesidad (Notwendigkeit): la de ser Cristo la enajenación de lo divino (entäusserung des Göttlichen) para ser así el representante del reino de Dios ${ }^{72}$.

Pero a la muerte de Cristo, que es la expresión más dramática de la muerte de Dios, le ha seguido la resurrección y con ello ha quedado vencida la muerte, la limitación y la finitud. Decir esta verdad fue la verdadera revolución de Cristo. La enseñanza que se dedujera de aquí no podría por menos de ser también "revolucionaria" ${ }^{73}$. La muerte de Cristo fue una muerte ejemplar, como lo fue la de Sócrates; pero la de Cristo supera a la de Sócrates por su calidad de ser reveladora de Dios y porque por ella comienza la definitiva conversión de la conciencia (Umkehrung des Bewusstseins). Esta muerte, con su consiguiente resurrección, es el centro de la comprensión plenaria de la Religión y de Dios. Por ella ha sido superada, transida de Dios o trascendida la inmediatez de 10 finito. Para el lenguaje dialéctico, "la muerte de Cristo, dice Hegel ", es la muerte de la muerte, la negación de la negación".

\section{EL PALPITO DE LA COMUNIDAD}

Aunque con muy poca frecuencia, aflora, de vez en cuando, en esta Filosofía de la Religión de Hegel, el tema del amor. Es un tema que, por su referencia antropológica y por su fácil aplicación a las vivencias personales, ofrece sin duda el modelo más comprensible de los tres momentos dialécticos. Hablando de la mitología griega nos dice Hegel que "Eros, el más antiguo de los dioses, es el que

\footnotetext{
70. LASSON, 137: "Gott als der konkrete Gott".

71. LASSON, 141.

72. LASSON, 137.

73. LASSON, 169.

74. LASSON, 167: “...Der Tod Christi ist aber der Tod dieses Todes selbst, die Negation der Negation".
} 
une lo separado" "5. En la vida de la Comunidad cristiana será también el amor el que ofrecerá el mejor vínculo de unión entre los creyentes y dará la fuerza de vivir el presente proyectado sobre el porvenir, en lo que consiste la esperanza. Todo ello, naturalmente, mediante la asunción racional del hecho de que la presencia de Dios sigue latiendo y desarrollándose en la medida en que esa misma Comunidad, a nivel de individuos y de colectividad, va tomando conciencia de la superación de su finitud por la fusión en esa misma Presencia.

Hegel comienza por hacer constar explícitamente que es en la Religión cristiana donde mejor se define a Dios diciendo que "Dios es amor". "La determinación fundamental en el Reino de Dios es la presencia de Dios, de tal suerte que a los miembros de este reino se les recomienda no solamente el amor del hombre hacia el hombre sino también el de tomar conciencia de que Dios es amor" "76. Reconciliado el mundo por la muerte de Cristo, cúspide de la prueba del amor de Dios a este mundo y sus hombres, "la conciencia de la Comunidad pasa así del hombre propiamente dicho, al HombreDios..." Ha quedado asumida la alteridad y "para la Comunidad es ésta ya la Historia de la aparición de Dios. $Y$ esta historia es una Historia divina a través de la cual la Comunidad llega a la conciencia de la verdad" "7. La Comunidad se forma, propiamente, cuando la aparición sensible de Cristo desaparece y su presencia ha de vivirse sólo en y por el Espíritu. Ha pasado a ser Historia, pero queda también en presente conteniendo a la vez el pasádo y el porvenir. Es el momento, único ${ }^{78}$ en que la exterioridad queda interiorizada $\mathrm{y}$ late en la Comunidad la presencia invisible del Consolador (Tröster). Se ha espiritualizado la forma sensible; el mismo Ahora (Jetzt) es como pasado y asumido y comienza a actuar el porvenir. Aqui está propiamente el punto inicial de la formación (Bildung) de la Comunidad ${ }^{79}$. Ha habido una conversión hacia lo espiritual; "el espiritu se objetiva a sí mismo como unidad de los precedentes y la alteridad (Anderssein) del segundo es absorbida (aufgehoben) en el tercero que es el amor eterno" 80.

Hegel se mueve a sus anchas en este terreno de las abstraccio-

75. Lecciones de Filosofía de la Historia Universal, II, 93.

76. LASSON, II, II ${ }^{\mathrm{a}}, 170$.

77. LASSON, 173.

78. LASSON, 168: "Sie ist für die Vorstellung ein einseitiges Moment, dem in die Gegenwart hat $\mathrm{zu}$ Momente in sich die Vergangenheit und die Zukunft".

79. LASSON, 169.

80. LASSON, 197. 
nes y que él llama especulativo. No es que no sepa cómo particularizar o descender a las aplicaciones concretas sino que realmente eso no le interesa o más bien diriamos que le interesa no particularizar ni clarificar demasiado lo que pudiera haber de valoración sobre la Iglesia institucionalizada, en su confesión protestante, que era la que él vivía. Las contradictorias interpretaciones a que su doctrina dio, posteriormente, lugar nos muestran sobradamente lo peligroso que le hubiera sido ese ceñirse a las valoraciones críticas de la vida de la Comunidad religiosa en que a él le interesaba verse, o que le vieran, integrado. De ahi su siempre posible ambigüedad en el momento de una hermenéutica concreta de aplicaciones a la estructuración o jerarquización de las vivencias religiosas y sús formulaciones tanto doctrinales como cultuales dentro de la propia Comunidad eclesial. Por ello, Hegel insiste en que lo decisivo es "el contenido" de la Comunidad y que éste es "la conciencia de Dios como espíritu y que este espíritu, en su existencia y su realización, es la Comunidad". Incluso "ya no son las palabras de Cristo, sino la actividad de la propia Comunidad, de la Iglesia" ${ }^{81}$ lo que ha de preocuparnos. Lo que, de hecho, esa actividad produce o logra o, tal vez, malogra o desvirtúa, parece expresamente como no concernirle. "La forma empírica de esta producción mediante las reuniones eclesiales (Kircheversammlungen), concilios, etc., ya no nos concierne a nosotros. Lo que nos concierne es: ¿cuál es el contenido del en-y para-sí? Este contenido es el que debe ser justificado mediante la Filosofía y no mediante la Historia. Lo que hace el espiritu no es ninguna historia (Historie). Su quehacer es del presente" ${ }^{82}$. "El paso de la singularidad de la idea divina en cada uno de los individuos para retornar a la unidad del Espíritu se logra mediante la concienciación de la Comunidad revelando en ella la presencia de Dios, viniendo de ese modo el Espíritu a ser real y universal" ${ }^{83}$.

Una de las formas de ese latido del espíritu en la Comunidad es su reflejo en la fe y en las enseñanzas de la Iglesia. Pero no esperemos que Hegel cambie aquí de proceder explicitativo hacia lo usual, ritual o empirico. Fe es la creencia en la verdad, la certeza en la verdad, la certeza en la verdad absoluta que es Dios y que Dios es

81. LASSON, 198.

82. LASSON, 198.

83. LASSON, 164. El no pasar a ese conocimiento del Reino del Espíritu sería mantenerse en el Reino del Hijo, cosa que Hegel achaca, muy simplificadoramente, a la Iglesia Católica por el hecho de venerar sobre todo a la Madre de Dios y a los Santos y por el hecho también de limitar ese espíritu a lo que ella decreta (was sie dekretiert) (LASSON, 197. 
espíritu y que en serlo y en su actividad en cuanto tal consiste su realización (seine Verwirklichung). La enseñanza de la Iglesia cristiana es de capital importancia para despertar sentimientos que vengan originados de la verdad; debe substraerse esta doctrina de los albures de "perspectivas caprichosas". La doctrina no se crea en la Iglesia, sino que es desarrollada en ella por la presencialidad del espíritu" " 84.

El tema del amor que es, repetimos, el de más fácil y comprensible expresividad dialéctica por sus tres términos de amante (seren-si), amado (ser innovado o innovante, ser-de-otro-modo) y enriquecimiento de ambos en la apropiación asuntiva de la mutua donación (ser-para-sí) queda de esta forma plenamente logicizado en el concepto de Dios, en su esencialización temporal y en la evolución de las formas más representativas de lo religioso que tejen el entramado de la historia y que culminan en las doctrinas y vivencias de la Comunidad cristiana. Hegel tomó bien a pecho el ridiculizar a Schleiermacher por hacer consistir la esencia de lo religioso en la dependencia y en el sentimiento. Todo ha de ser y verse racional y racionalizado. Cuando se habla del corazón del hombre, no hay que olvidarse de que es, dice Hegel, "un corazón que piensa, y lo que hay de religión en ese corazón y en los sentimientos que de él nacen es un pensamiento de esos sentimientos y de ese corazón" ${ }^{85}$. Este es, pues, el corazón cuyo latido debe escucharse y fomentarse en la vida de la Comunidad cristiana.

Aunque he procurado pasar por alto la casi totalidad de las referencias que en estos volúmenes Hegel hace a las formas de culto, de piedad $y$ de otras manifestaciones religiosas externas, la verdad es que rara vez estas referencias favorecen 0 amplian de hecho el ámbito racional de la temática hegeliana. Creo que este ceñimiento a lo más extrictamente ligado al engranaje filosófico responde a lo que, dentro de un obligado resumen, desearía el mismo Hegel que se hiciera resaltar. El empedrado de textos literales y seleccionados

84. LASSON, II, II ${ }^{\mathrm{a}}$ : "(Die Lehre) der Kirche (wird) in der Kirche nicht erschaffen, aber ausgebildete durch (den) gegenwärtigen Geist".

85. IASSON, II, IIa, 23 : “...ist denkendes Herz und denkendes Gefühl, und was von Religion in diesem Herzen und Gefühl ist, ist ein Denken dieses Herzens, Gefühls". Es llamativa la coincidencia de expresiones, aunque con diverso contexto y connotación, entre estas frases de Hegel y otras idénticas de Heidegger. Aunque interesante, no es esta la ocasión de entrar en el tema. Como referencia al contexto heideggeriano; cf. J. L. CANCELO, "En recuerdo de Martín Heidegger. Un pensar en camino": Arbor 373, (1977) 46. Entre otros lugares, en Heidegger, pueden verse: Gelassenheit, 1959, 62; Vorträge und Aufsätze, 1954, 139; Was heisst Denken, 1954, 157-159. 
con que van cargadas estas páginas ha obedecido al propósito de que sea Hegel, en la medida de lo posible, quien haga siempre su propio comentario. Queda de esta manera el campo abierto a las interpretaciones de quienes busquen otros propósitos doctrinales distintos de este central que es el enhebramiento dialéctico de los grandes temas de este Tratado. Se trataba, deciamos al principio, de Filosofía de la Religión o bien de la segunda configuración dialéctica del Espíritu Absoluto que apalanca el salto a la Filosofía, en cuanto tal, como configuración última y definitiva de ese Espíritu. La Religión debe mostrar la verdad de un modo accesible a todos. Pero la captación de esa verdad tiene distintos niveles y dimensiones. Uno es el de todos los hombres, sencillos fieles o creyentes de esa verdad y cumplidores de las prácticas cultuales y morales que ella exige, y otro el de aquellos que deben y tienen que buscar y darle su justificación filosófica. Hegel trae a colación el dicho de Homero de que algunas estrellas tienen dos nombres: uno el de la lengua de los dioses y otro el de la de los hombres efímeros. Paralelamente, en la Religión hay dos lenguajes: el del común de los mortales, que es el de la "representación" y el lenguaje filosófico que trata de expresar ese mismo contenido en lo que tiene de vida y justificación en la historia del concepto concreto ${ }^{86}$. Es a este lenguaje al que ha pretendido mantenerse fiel Hegel.

"La meta de estas lecciones - se nos dice al final del Tratado- era reconciliar la Razón con la Religión en sus diversas configuraciones, de reconocer, al menos, a éstas como necesarias" ${ }^{87}$. En cuanto a resultados determinados para su momento histórico, Hegel cree haber logrado superar las posiciones de los llamados "ilustrados" y, a la vez, haber dado un nuevo impulso de penetración, sin miedos y con audacia, al estudio de la temática religiosa, mostrando no sólo la inanidad de los supuestos conflictos entre la Razón y la Fe, sino haciendo ver además la auténtica y pura racionalidad dialéctica de la Religión. Pero justamente para ello, la Religión "debe refugiarse en la Filosofía": in die Philosophie sich flüchten ${ }^{88}$. El convencimiento personal de Hegel sobre este logro, para quien reflexione detenidamente sobre su trabajo, le hace formular, como final, este ferviente deseo": Ojalá (mögen) que estas lecciones contribuyan a dar una mejor dirección en el conocimien-

86. Enzyklopädie der ph. Wiss., Vorwort, 2. Aufl.

87. LASSON, II, IIa, 231.

88. LASSON, II, II ${ }^{\mathrm{a}}, 231$. 
to racional de la Religión y, en general, a estimular una promoción o progreso (Beförderung) de la religiosidad" ${ }^{8}$.

Consecuentes con nuestro planteamiento, sería más que presuntuoso pretender dar aquí algo asi como conclusiones definitivas y cerradas de valoración critica sobre lo que implica, supone y abarca esta ingente acumulación de materiales y problemas que esta Filosofía de la Religión ha analizado o sesgado al menos. Los especialistas de Teología natural o de Teologia en general tendrán mucho todavia que analizar, revisar, corregir y matizar antes de acercarse a esas conclusiones últimas a que nos referimos, si es que, de algún modo, es posible alcanzarlas o al menos aludirlas.

Algo, con todo, se me antoja suficientemente claro y que se puede enunciar con ciertas garantías de verdadero enjuiciamiento general. Esta Filosofía de la Religión nos muestra la culminación de un proceso ideológico y de estructuraciones culturales de las que Hegel representa una última piedra clave en el arco de la bóveda de los tratadistas de su tiempo: el último grito de la razón secularizada y secularizadora de todo el amplio mundo de la temática religiosa. Por encima de las apelaciones y recursos a la Historia y por encima de los análisis minuciosos, siempre reincidentes en la misma línea racional preintuída o predeterminada, reiterativos hasta el aburrimiento, parece cernirse un halo romántico unificador, abarcador e idealísticamente desmesurado, que proyecta el "deber ser" de Dios partiendo de la inexorabilidad del devenir dialéctico como divina necesidad. $\mathrm{Y}$, por ello, lo que se llama "racional" emerge de nuevo, como un otro Hado indómito al que ha de someterse, en su dinámica procesual de Dios vivo, y precisamente para seguir vivo, el obrar eterno y temporal de la divinidad. La racionalización se lleva hasta su extremo último; ya no podrá haber un "Deus absconditus", sino sencillamente, y para siempre, un "Deus revelatus" que quiere decir un Dios transparentado por sí mismo o, lo que es igual, taladrado por esa irrompible y diamantina Razón que se llama la Dialéctica. Se ha evaporado, también definitivamente, el misterio y la inefabilidad de Dios. Un Dios sin secretos pero además también sin libertad. La temporalización se ha introyectado en el Absoluto y el absoluto se ha historificado, anonadándose, para revelarse y conocerse. La espléndida e impresionante racionalización se convierte en ciega y siniestra irracionalidad, para realizar obligatoria-

89. LASSON, 232. 
mente "el mayestático caminar de Dios" 90. El torrente del devenir viene encauzado, guiado, atraido por el abismo sin fondo ni fronteras de la necesidad decretada de lo irracional.

La pregunta extrema surge, entonces, irremisiblemente: ¿Hemos superado a Grecia o hemos vuelto otra vez a caer y pecar en ella? ¿Seguimos presos, sin remisión, sin reabsorción, de nuestra propia obra histórica? Desechada y proscrita gloriosamente la noción éstática de ser, hemos conquistado sin duđa la noción dinámica, viva, fluyente e incontenible. Transferida a la Teología racional $\mathrm{y}$ asumidas en ella las versiones de la revelación bíblica, Dios no puede ser ya el "motor inmóvil", ni el inmutable, si ha de ser un Dios vivo y que crea el mundo y en el mundo, y libremente, la libertad. Ha de ser, pues, un Dios también histórico y también libre. Pero, ¿qué nuevas categorias mentales habremos de crear en el futuro para poder vislumbrar, al menos, de un modo analógico, coherente $\mathrm{y}$ no necesitante, esa nueva y patente y recién descubierta historicidad de Dios?

\author{
RAMrro FlóRez \\ Universidad Autónoma \\ Facultad de Filosofía y Letras \\ MADRID
}

90. Cf. I, ILJIN: Die Philosophie Hegels als kontemplative Gotteslehre. Bern, 1946, 360-362, donde Iljin expone patéticamente todo el amplio alcance de este irracionalismo hegeliano. 